\title{
DA CENTRALIDADE POLÍTICA À CENTRALIDADE DO CORPO TRANSUMANO: MOVIMENTOS DA TERCEIRA VIRADA DISTÓPICA NA LITERATURA
}

\author{
Eduardo Marks de Marques*
}

Universidade Federal de Pelotas

Resumo: Muito se discute o caráter político dos romances distópicos da chamada segunda virada (do fim do século XIX a meados da década de 1950), vistos especialmente como críticas contundentes a regimes políticos totalitários. No entanto, uma nova vertente de romances distópicos, nos últimos 30 anos, tem discutido o impacto do desejo criado pelo capitalismo tardio na transfiguração do corpo, o que tem sido central para a construção de ideias pós-humanas e transumanas. O presente artigo almeja discutir as mudanças encontradas na literatura distópica de língua inglesa ao longo do século XX para propor uma terceira virada distópica na literatura, a partir dos escritos de Fredric Jameson sobre ficção científica e utopia, nos últimos trinta anos e centrando-se nas diversas configurações do corpo construídas a partir do desejo imposto pelo capitalismo tardio e seu impacto no modo de pensamento póshumanista e transumanista. Para tanto, exemplos de vários romances pertencentes a tal tendência são brevemente discutidos a fim de criar um panorama teórico-crítico que embase tal proposta.

Palavras-chave: Distopias. Pós-humanismo. Transumanismo. Utopia. Ficção especulativa.

O número mais recente do periódico Anuário de Literatura (v.18, n.2), traz um artigo, intitulado "Teoria Crítica e Literatura: a distopia como ferramenta de análise radical da modernidade", de Leomir Cardoso Hilário. Nele, Hilário propõe-se a aplicar alguns preceitos dos pensadores da Escola de Frankfurt para propor que o gênero distópico (especialmente aqueles títulos que compõem o que chamo de distopias modernas, mas que o crítico Gregory Claeys identifica como sendo pertencentes à segunda virada distópica) seja visto como ferramenta de análise radical da modernidade e propõe "que o gênero literário conhecido como distopia nos fornece elementos para pensar criticamente a contemporaneidade,

Esta obra está licenciada sob uma Licença Creative Commons.

\footnotetext{
* Professor Adjunto da Universidade Federal de Pelotas, doutor em Australian Literature and Cultural History University of Queensland (2007) e pós-doutorado em Estudos Literários, ênfase em Teoria Literária pela Universidade Federal de Minas Gerais (2014).
} 
sobretudo com relação à segunda metade do século XX e início do século XXI" (HILÁRIO, 2013, p. 202). A partir de algumas considerações feitas pelo autor, gostaria de expandir sua proposta de leitura das distopias (e, consequentemente, das utopias) apresentando uma visão distinta daquela.

Nesse contexto, é importante salientar o recente ressurgimento dos estudos de eutopia e distopia, especialmente dentro dos estudos literários, nos últimos trinta anos. Se a eutopia enquanto gênero surge nos discursos platônicos sobre a cidade-estado ideal e é consolidada no livro de Thomas Morus, a distopia, aquela construção que Rafaella Baccolini e Tom Moylan definem como "o lado negro da utopia” (BACCOLINI E MOYLAN, 2003, p.1) surge não no século XX mas, sim, no século XVIII, através de panfletos mostrando as possibilidades negativas de construção de mundo pós-Revolução Francesa (CLAEYS, 2010, p.110). A confluência de fatores como a centralidade da razão e da ciência como elementos norteadores da vida proposta pelo iluminismo e, sua consequência direta, o desenvolvimento urbano e industrial da Europa durante o século XIX aproxima as construções de mundos negativos de uma possível causa da rápida mudança de padrões de vida imposta pelo rápido desenvolvimento tecnológico. O gênero da ficção científica, cuja gênese pode ser traçada ao Frankenstein, de Mary Shelley, de 1818, amalgama-se às distopias especialmente por conta dos romances de H.G. Wells, na virada do século XIX para o século XX.

As distopias modernas, como Nós (1921), de Yevgeny Zamyatin, Admirável Mundo Novo (1937), de Aldous Huxley, 1984 (1948), de George Orwell e Fahrenheit 451 (1953), de Ray Bradbury, trazem um forte componente político em suas narrativas e tal tendência pode ser identificada através da influência de uma dos mais importantes textos utópicos do século XIX: O Manifesto Comunista (1848), de Karl Marx e Friedrich Engels. Há duas dimensões para a afirmação sobre a influência do Manifesto na criação das distopias literárias da primeira metade do século XX. A primeira delas é relativa ao caráter prescritivo do texto. $O$ Manifesto Comunista serve, entre outras coisas, como um plano para mudança social e econômica através dos preceitos defendidos por Marx e Engels (e, também, em igual grau, como uma crítica aos experimentos sociais criados pelos chamados socialistas utópicos como Fourier e Saint-Simon pois, para os autores do Manifesto, uma verdadeira sociedade socialista/comunista não poderia sobreviver como um enclave dentro de uma sociedade capitalista e, por isso, estariam fadados ao desaparecimento, como de fato ocorreu). A segunda dimensão, tida como a mais definitiva, relaciona-se com o uso do Manifesto para a base da revolução bolchevique de 1917 e a consequente criação da União Soviética, em 1922. 
O uso da força para a manutenção do estado soviético após a morte de Lênin e a subsequente criação de um modelo comunista totalitário por Stalin (em oposição à transição natural de um estado capitalista forte para um estado socialista forte, conforme defendia Marx) surge como um sinal de alerta ao Ocidente. A narrativa distópica de Zamyatin, escrita a partir de suas impressões dentro do regime soviético, enfatizando a força do Partido Comunista em interferir com os atributos mais básicos da vida privada, como o direito à privacidade, por exemplo, serve como base para as distopias ocidentais.

Isso posto, cabe citar que toda utopia faz perguntas ou sobre a realidade futura como possibilidade, ou sobre a realidade presente como fato (TOWER SARGENT, 2010, p. 5). Uma primeira conclusão a partir de tal visão é que utopia é uma construção de mundo que não existe $(u+$ topos, o não-lugar $)$ mas que não necessariamente seja ideal. Aliás, tal problematização já aparece em Morus a partir do questionamento sobre a distinção entre utopia e eutopia (eu + topos, o lugar bom), termos que, em inglês, compartilham a mesma pronúncia. O espírito utópico sempre prevê e/ou propõe mudanças e, via de regra, tais mudanças sempre são para melhor. Logo, toda distopia é utópica e, assim, tais noções não são mutuamente opostas. Uma análise superficial das sociedades do Estado-Nação, de Huxley, e de Oceania, de Orwell, mostra-nos que tais estados não foram pensados e criados como distopias por seus líderes mas, sim, como eutopias, uma vez que - ao menos para parte da população desses lugares - houve uma melhora nas condições de vida em relação a condições anteriores (MARKS DE MARQUES, 2013b, p. 32). Ainda assim, a crítica política presente nestas duas distopias é muito mais complexa do que uma simples crítica ao modelo socioeconômico apresentado. Em Admirável Mundo Novo, não é o sistema capitalista que figura no centro da crítica (ainda que ele tenha, inclusive, instaurado uma nova cronologia no mundo onde Henry Ford toma o papel de Cristo como marcador do início de uma nova era) mas, sim, a (ainda) crescente dependência dos seres humanos à tecnologia, a ponto de mediar todas as relações humanas substituindo, por exemplo, os afetos. Em 1984, ao contrário do que uma leitura superficial pode sugerir, Orwell não critica o modelo socialista de organização sociopolítica mas, sim, a então indissociabilidade de tal modelo a um regime monopartidário e totalitário, que tem como principal objetivo a constante modificação da verdade (presente e histórica).

O peso político dos regimes totalitários como elemento central dos romances acima metamorfosearam-se e serviram como analogia para a apropriação dos modelos distópicos por escritoras feministas a partir dos anos 1960 para denunciar e questionar a opressão às 
mulheres e os modelos sociais impostos pelo patriarcado ocidental. Duas vertentes temáticas são visíveis. Por um lado, romances como A Mão Esquerda da Escuridão (1969), de Ursula LeGuin, por exemplo, utilizam-se de elementos da ficção científica para propor modelos de sociedade com construções não-binárias de gênero, sugerindo que apenas fora da cultura terrestre (ou terráquea) pode-se pensar em configurações sociais distintas. Por outro lado, romances como O Conto da Aia (1985), de Margaret Atwood, exploram os elementos culturais do patriarcado - religião, no caso do romance citado - como centrais para a manutenção de uma sociedade que não só oprime as mulheres tira delas o direito à voz e à figurarem na história.

A aproximação do gênero distópico com o da ficção científica vem, por mais de um século, sendo alvo de análises a respeito do caráter especulativo de tais obras. Se é verdade que muitos dos elementos presentes nas narrativas de Huxley, Orwell e Bradbury tornaram-se reais em nossas vidas de uma forma ou de outra, isso acaba sendo menos relevante do que o movimento cronológico das eutopias para as distopias. Toda eutopia existe no presente do narrador. O modelo (e)utópico clássico, não surpreendentemente, é o da narrativa de viagem: um viajante retorna para sua terra natal após ter experimentado a vida em um lugar distante (e, essencialmente, inexistente) e passa a descrever a organização social, econômica e política desse lugar. O importante é que tal narrativa só faz sentido por ser criada para um leitorado contemporâneo ao do narrador e, por isso, o não-lugar é presente. As distopias, no entanto, trabalham com a noção de eucronia (VIEIRA, 2010, p. 9): mais do que a ideia superficial de que o futuro-enquanto-presente seja sombrio, há a ideia latente de que a realização utópica só pode realizar-se completamente no futuro-enquanto-futuro e, portanto, o não-lugar ideal não existe no presente da narrativa.

Logo, é possível ver que as distopias, ao mesmo tempo que negam a forma através das quais as narrativas eutópicas clássicas foram constituídas, atualizam-nas ao incorporar os ideais científicos e tecnológicos (e o temor envolvido nos mesmos) especialmente durante a era Vitoriana. Como o século XX foi o século tecnológico por excelência, faz todo sentido que o gênero distópico não tenha desaparecido completamente. Toda utopia (positiva ou negativa) é uma resposta ao contexto presente de sua produção. Isso posto, as narrativas distópicas dos últimos 30 anos refletem as tensões sociohistóricas do período, configurando o que eu denomino terceira virada distópica (MARKS DE MARQUES, 2013a, p. 1-5). Pode-se marcar o início de tal tendência na tese (já revisada) de Francis Fukuyama sobre o fim da história. No controverso livro The End of History and the Last Man (1992), Fukuyama 
defende que o colapso da União Soviética marca a vitória do capitalismo e das democracias liberais ocidentais, de modo que a humanidade teria, então, atingido o ápice de seu desenvolvimento sociohistórico. O fim da história marca, para o filósofo, o fim da utopia:

\begin{abstract}
Nós que vivemos em democracias liberais estáveis e de longa data encaramos uma situação incomum. No tempo de nossos avós, várias pessoas razoáveis podiam prever um futuro socialista radiante no qual a propriedade privada e o capitalismo teriam sido abolidos e no qual a própria política teria sido de alguma forma superada. Hoje em dia, por contraste, temos problemas em imaginar um mundo que seja radicalmente melhor do que o nosso próprio mundo ou um futuro que não seja essencialmente democrático e capitalista. Dentro de tal quadro, obviamente, muitas coisas podem ser melhoradas: poderíamos abrigar os desabrigados, garantir oportunidades para as minorias e para as mulheres, melhorar a competitividade e criar novos empregos. Podemos, também, imaginar mundos futuros que sejam significantemente piores do que este que conhecemos hoje, no qual a intolerância nacional, racial ou religiosa retorne ou no qual nós sejamos destruídos pela guerra ou por um colapso ambiental. Mas nós não conseguimos imaginar um mundo que nos seja essencialmente diferente do nosso momento presente e, ao mesmo tempo, melhor. Outras eras, menos reflexivas, também pensavam ser as melhores possíveis mas chegamos a tal conclusão, como foi possível, através da busca de alternativas que pensamos poder ser melhores do que a democracia liberal. ${ }^{1}$ (FUKUYAMA, 1992, p. 42, tradução nossa)
\end{abstract}

A morte da utopia, para Fukuyama, garante a permanência e a centralidade da distopia como único modo imaginativo e especulativo possível após o fím da história. A analogia entre história e utopia (enquanto desejo de mudança) é inevitável. No entanto, tal qual a ideia de história ligada exclusivamente a uma perspectiva político-econômica, a utopia não morreu; mesmo que ela possa ter-se transfigurado em ficção especulativa ou distopias, o espírito utópico permanece presente e, interessantemente, tornou-se extremamente crítico da cultura surgida ao redor e por causa do modo capitalista tardio finissecular. Dunja H. Mohr, em seu ensaio intitulado "Transgressive Utopian Dystopias: The Postmodern Reappearance of Utopia in the Disguise of Dystopia” (2007), parte da tese sobre o fim da história para desenvolver a ideia da transmutação dos ideais utópicos na pós-modernidade através da noção de "distopias utópicas transgressivas" ("transgressive utopian dystopias"). Mohr parte das distopias feministas e identifica o que chama de elemento transgressivo:

\footnotetext{
${ }^{1}$ We who live in stable, long-standing liberal democracies face an unusual situation. In our grandparents' time, many reasonable people could foresee a radiant socialist future in which private property and capitalism had been abolished, and in which politics itself was somehow overcome. Today, by contrast, we have trouble imagining a world that is radically better than our own, or a future that is not essentially democratic and capitalist. Within that framework, of course, many things could be improved: we could house the homeless, guarantee opportunity for minorities and women, improve competitiveness, and create new jobs. We can also imagine future worlds that are significantly worse than what we know now, in which national, racial, or religious intolerance makes a comeback, or in which we are overwhelmed by war or environmental collapse. But we cannot picture to ourselves a world that is essentially different from the present one, and at the same time better. Other, less reflective ages also thought of themselves as the best, but we arrive at this conclusion exhausted, as it were, from the pursuit of alternatives we felt had to be better than liberal democracy. (FUKUYAMA, 1992, p. 42)
} 
[as] preocupações temáticas de tais 'distopias' envolvem transgressões de sujeito/objeto, masculino/feminino, humano/animal e humano/alienígena ou humano/não-humano, mestre/escravo, natureza/criação, natureza/cultura, mente/corpo, sanidade/loucura, eu/outro, letramento/oralidade, códigos/estereótipos, a relação entre mito/história em relação à (im)possibilidade de uma representação da realidade e da(s) verdade(s). Os textos rejeitam "uma conexão determinista, teleológica entre passado, presente e futuro" . . . e oferecem visões alternativas múltiplas ou heterogêneas ao invés da posse de uma realidade e $u m$ futuro. ${ }^{2}$ (MOHR, 2007, p. 12, tradução nossa)

A dinâmica utópica/distópica é, então, orientada a uma nova compreensão pósmoderna da utopia como um projeto que rejeita as universalidades das blueprints, planos teóricos para a construção de sociedades ideais que ignoram as posições individuais. Isso significa que as utopias pós-modernas contemplam a realidade como sendo multifacetada e não excluem o fato primordial que eutopias e distopias são, na realidade, faces distintas de uma mesma construção de mundo. Margaret Atwood, em seu estudo sobre ficção especulativa chamado In Other Worlds: SF and the Human Imagination (2011) chama tal gênero de "ustopia" (ATWOOD, 2011, p. 66), cujo amálgama pode ser visto mesmo no nome, que mistura as noções de utopia e distopia.

No entanto, é importante explicitar que o impulso utópico, mesmo com a aproximação dele com as distopias, jamais morreu. Tal impulso é o foco que o crítico marxista Fredric Jameson analisa em Archaeologies of the Future: The Desire Called Utopia and Other Science Fictions (2005). Nele, Jameson traça as conexões entre utopia e política especialmente no século XX - uma vez que o modo de pensar utópico fora tido como o único possível para construir qualquer alternativa ao modo de organização capitalista. Se é verdade que qualquer modo de pensamento anticapitalista requer (ou requereu) um entendimento do que seria necessário para a construção de uma vida melhor (significando, obviamente, um sentimento geral de desencanto com o que quer que "vida real" signifique), a construção prática de tais utopias transformaram-se em distopias, em "um desejo à uniformidade e pureza ideal de um sistema perfeito que sempre teve de ser imposto à força sobre seus sujeitos imperfeitos e relutantes" (JAMESON, 2005, p. xi, tradução nossa) ${ }^{3}$, conectando, assim, os experimentos comunistas com regimes totalitários. Logo, torna-se fácil identificar os enlaces complexos entre utopia e distopias.

\footnotetext{
2 [t]he thematic concerns of these 'dystopias' involve transgressions of subject/object, male/female, human/animal and human/alien or human/non-human, master/slave, nature/nurture, nature/culture, mind/body, sanity/madness, self/other, literacy/orality, codes/ stereotypes, the relation between myth/history with regard to the (im)pos-sibility of a representation of reality and truth(s). The texts reject "a determinist, teleological link between past, present and future"... and offer multiple or heterogeneous alternative views rather than the possession of one reality and $a$ future. (MOHR, 2007, p. 12)

3 "a will to uniformity and the ideal purity of a perfect system that always had to be imposed by force on its imperfect and reluctant subjects"
} 
Através de uma leitura profunda de filosofia moderna, Jameson identifica dois grandes eixos da utopia, considerando o texto e Thomas Morus como o ponto de partida: o eixo do programa utópico e o eixo do impulso utópico (JAMESON, 2005, p. 3-4). Reduzindo ambos os eixos a seus componentes mínimos, vê-se que o programa utópico organiza-se em orientação pelo presente e conecta-se, ainda que tangencialmente, ao que muitos pensadores das utopias chamam de blueprint (ou "planta-baixa", isto é, a ideia de um plano único que possa ser consolidado e reproduzido igualmente em todos os lugares, ideia a qual foi diretamente rejeitada por Marx e seus sucessores em suas críticas ao socialismo utópico). $\mathrm{O}$ programa utópico deve ser visto como um trabalho em andamento, o qual pode envolver, por exemplo, uma reorganização do locus urbano ao redor das ideias de uma revolução sustentada, entre outras coisas, pela práxis e pela literatura.

O impulso utópico, por outro lado, orienta-se para o futuro e tem como preocupação a cristalização da utopia não somente ao manter vivos os ideais revolucionários presentes no programa mas, principalmente, ao prevenir o aparecimento de ideias contrarrevolucionárias que possam colocar a utopia em risco. No entanto, de acordo com Jameson, o elemento mais importante para a análise do impulso utópico é, sem dúvida, o hermenêutico, o que envolve corporalidade, cronologia e coletividade, conforme pode ser visto no esquema reproduzido abaixo.

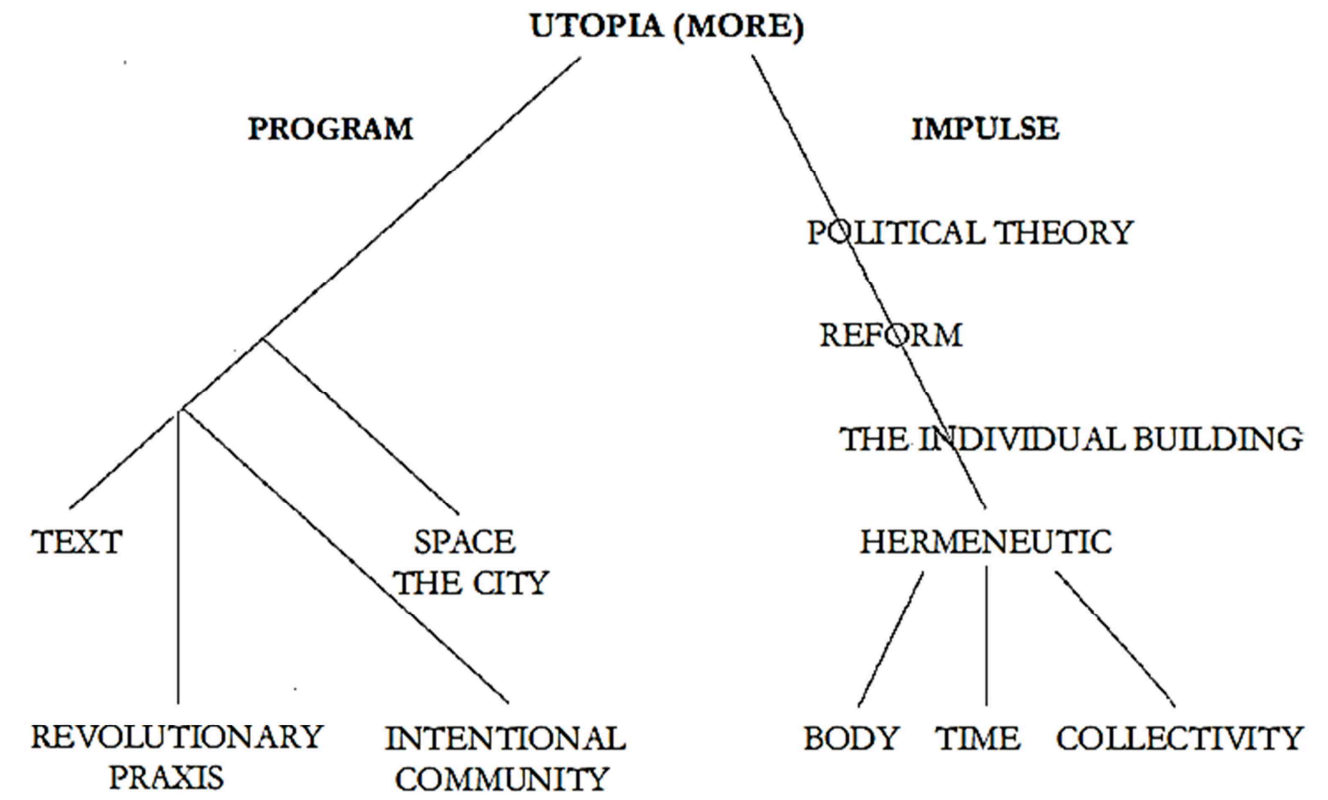

1 - Diagrama de Jameson para o programa e impulso utópicos (JAMESON, 2005, p. 4) 
O corpo material torna-se central no entendimento das utopias contemporâneas. Jameson afirma que

[o] materialismo já está onipresente em uma atenção ao corpo que busca corrigir qualquer idealismo ou espiritualismo remanescente neste sistema. A corporalidade utópica é, no entanto, uma assombração, que investe até mesmo nos produtos mais subordinados e modestos da vida cotidiana, tais como aspirinas, laxantes e desodorantes, transplantes de órgãos e cirurgia plástica, todos abrigando promessas mudas de um corpo transfigurado. ${ }^{4}$ (JAMESON, 2005, p. 6, tradução nossa)

Torna-se ainda mais sintomático, então, que o início aceito do gênero de ficção científica na literatura tenha sido o Frankenstein, romance em que há não somente uma metáfora do embate homem versus Deus mas, principalmente, a criação de um corpo transfigurado mas que almejava a perfeição, promessa das utopias (principalmente distópicas) contemporâneas.

Se o elemento corporal é importante para a compreensão dos novos modelos utópicos (distópicos, principalmente), especialmente considerando-se que muitos dos binários que Mohr identifica como sendo transgredidos pelo novo modelo de distopias estão centrados em um entendimento do corpo, que corpo é este que permeia e media as relações entre si mesmo e o mundo? Primeiramente, considerando o que Francis Fukuyama afirmou, parece justo dizer que tal corpo é essencialmente capitalista, cuja existência é validada através da noção de desejo. O sociólogo Bryan S. Turner, em seu livro The Body and Society: Explorations in Social Theory (2008) identifica tal corpo afirmando que:

\begin{abstract}
Nossas atitudes frente à sexualidade, aos papeis sociais da mulher e ao gênero são, em parte, o legado secreto do cristianismo feudal e das exigências de relações de propriedade nos modos de produção baseados na apropriação privada. Nossas atitudes também foram moldadas pela história antiga da vida familiar e do lar patriarcal. No capitalismo tardio, tais atitudes, em muitas formas, não mais se sujeitam às exigências reais da economia ou da estrutura social de uma sociedade capitalista que é organizada ao redor da propriedade corporativa. Porque propriedade e investimentos estão, atualmente, concentrados em entidades corporativas, o capitalismo familiar não tem mais um papel central nas economias industriais. $\mathrm{O}$ capitalismo não precisa mais da unidade da família para garantir a distribuição da propriedade. Apesar do fato de que o capitalismo ainda possa ver o lar como uma unidade de consumo, não é uma exigência do capitalismo que tais lares sejam do tipo nuclear. O modo ascético de desejo, então, não é pertinente para as formas contemporâneas de acumulação de capital e é largamente impróprio para o consumo individual. $\mathrm{O}$ chão da fábrica deve ter regulações sociais para garantir uma produção contínua e eficiente mas, mesmo em casos de arranjos produtivos, é perfeitamente possível desabilitar a força de trabalho e substituí-la pelo trabalho frio das máquinas. $\mathrm{O}$ capitalismo moderno tente a nutrir um calculismo hedonista e uma personalidade
\end{abstract}

\footnotetext{
${ }^{4}[\mathrm{~m}]$ aterialism is already omnipresent in an attention to the body which seeks to correct any idealism or spiritualism lingering in this system. Utopian corporeality is however also a haunting, which invests even the most subordinate and shamefaced products of everyday life, such as aspirins, laxatives and deodorants, organ transplants and plastic surgery, all harboring muted promises of a transfigured body. (JAMESON, 2005, p. 6)
} 
narcisista. A cultura de consumo requer não a supressão do desejo mas sua manufatura, extensão e detalhe. ${ }^{5}$ (TURNER, 2008, p. 29, tradução nossa)

O corpo que rende-se ao desejo torna-se transfigurado por ele. O capitalismo requer a constante mutação de tal desejo e, também, do "calculismo hedonista e personalidade narcisista" que são partes deste corpo. Por outro lado, a construção de tal desejo está diretamente conectada à ascensão tecnológica do capitalismo tardio. O corpo humano, orgânico, não é mais autossustentável enquanto essência de humanidade. Em outras palavras: o capitalismo tecnológico, através da construção e manutenção do desejo, transformou-nos em ciborgues, seres cuja existência orgânica é falha e deve ser melhorada (e, se possível, prolongada) através da tecnologia. Em essência, tal relação redefine os conceitos de humanismo e humanidade e propõe as noções de transumanismo e pós-humanismo. Cary Wolfe (2010) define os termos como segue:

\begin{abstract}
[c]ertamente, o herdeiro mais conhecido da corrente "ciborgue" do pós-humanismo é o que tem sido chamado de "transumanismo" - um movimento que é dedicado, como afirma o jornalista e escritor Joel Garreau, "à melhoria das capacidades intelectuais, físicas e emocionais humanas, à eliminação de doenças e de sofrimento desnecessário e à uma dramática expansão da expectativa de vida. O que esses elementos têm em comum," continua Garreau, "é uma crença na evolução engendrada de 'pós-humanos,' definidos como seres 'cujas capacidades básicas excedem tão radicalmente aquelas dos humanos atuais a ponto de não mais serem considerados inequivocamente humanos por nossos padrões.' “'Transumano," ele conclui, "é a sua descrição daqueles que estão no processo de tornar-se póshumanos." Como uma das figuras centrais associadas ao transumanismo, o filósofo de Oxford Nick Bostrom, deixa claro, essa ideia de pós-humanismo deriva diretamente dos ideais de perfectibilidade, racionalidade e agência humanas, herdadas do humanismo renascentista e do Iluminismo. (E nisso, tem pouco em comum com a sensatez lúdica, irônica e ambivalente de Haraway no "Manifesto Ciborgue," que é suspeita - para colocar de forma leve — da capacidade da razão para conduzir, quanto mais otimizar, aquilo que ela forjou. $)^{6}$ (WOLFE, 2010, p. xiii, tradução nossa)
\end{abstract}

\footnotetext{
${ }^{5}$ Our attitudes towards sexuality, women's social roles and gender are in part the arcane legacy of feudal Christianity and the requirements of property relations in modes of production based on private appropriation. Our attitudes have also been shaped by the ancient history of family life and patriarchal household. In late capitalism these attitudes in many ways no longer conform to the actual requirements of the economy or to the social structure of a capitalist society which is organized around corporate ownership. Because property and investment are now concentrated in corporate bodies, family capitalism no longer plays a major role in industrial economies. Capitalism no longer requires the unity of the family in order to guarantee the distribution of property. Although capitalism may still require the household as a unit of consumption, it is not a requirement of capitalism that these households should be of the nuclear variety. The ascetic mode of desire is thus not pertinent to contemporary forms of capital accumulation and largely inappropriate to individual consumption. The factory floor must have social regulations to ensure continuous and efficient production, but even in the case of productive arrangements it is perfectly possible to de-skill the labour force and replace it with the dead labour of machinery. Modern capitalism tends to foster hedonistic calculation and a narcissistic personality. Consumer culture requires not the suppression of desire, but its manufacture, extension and detail. (TURNER, 2008, p. 29)

${ }^{6}$ [a]rguably the best-known inheritor of the "cyborg" strand of posthumanism is what is now being called "transhumanism" - a movement that is dedicated, as the journalist and writer Joel Garreau puts it, to "the enhancement of human intellectual, physical, and emotional capabilities, the elimination of disease and unnecessary suffering, and the dramatic extension of life span. What this network has in common," Garreau
} 
Considerando o exposto, gostaria de propor que a tendência encontrada nos romances distópicos, principalmente, publicados a partir da década de 1990 rejeitam a mera leitura política proposta pelas distopias clássicas e propõem a discussão dos ideais filosóficos e sociais do transumanismo e pós-humanismo a partir da centralidade do corpo transumano como resultante do modelo distópico. Os romances que compõem o que chamo de terceira virada distópica (MARKS DE MARQUES, 2013a, p.4) são aqueles em que o centro do ideal utópico não está em uma forma centralizada de controle social, político e/ou cultural sobre os indivíduos mas, sim, na relação entre o corpo orgânico (falho, defeituoso e imperfeito) e as promessas tecnológicas advindas do modelo capitalista pós-moderno em melhorá-lo e aperfeiçoá-lo e que, ao fazê-lo, negam a essência orgânica do ser humano. O ciborgue entidade parte orgânica, parte tecnológica — é, então, a principal mercadoria do capitalismo uma vez que o desejo, principal força-motriz do capitalismo tecnológico, nunca pode ser plenamente atendido. Em outras palavras: o embate entre as orientações organicista e tecnológica acerca da essência do ser humano tem sido central na construção de universos romanescos distópicos.

Um exemplo da centralidade do corpo enquanto força motriz das distopias contemporâneas pode ser visto em The Children of Men (1992), de P.D. James. No romance, situado na Inglaterra do ano 2021, o planeta inteiro sofre de uma epidemia absoluta de infertilidade masculina há mais de vinte e cinco anos. A morte do ser humano mais jovem da Terra, Joseph Ricardo, em uma briga de bar, serve de ponto de partida para que Theodore (Theo) Faron, um historiador e professor de história de Oxford comece a escrever em um diário. A partir daí, Theo constrói-se como o mantenedor de uma forma de conhecimento histórico que está prestes a tornar-se inútil e obsoleto uma vez que a preocupação humana no presente da narrativa não é com o entendimento do passado mas, sim, com a construção de um futuro. A partir das observações epistolares de Theo, o universo distópico no qual

continues, "is a belief in the engineered evolution of 'post-humans,' defined as beings 'whose basic capacities so radically exceed those of present humans as to no longer be unambiguously human by our current standards.' "“Transhuman,"” he concludes, "is their description of those who are in the process of becoming posthuman." As one of the central figures associated with transhumanism, the Oxford philosopher Nick Bostrom, makes clear, this sense of posthumanism derives directly from ideals of human perfectibility, rationality, and agency inherited from Renaissance humanism and the Enlightenment. (And in this, it has little in common with Haraway's playful, ironic, and ambivalent sensibility in "A Cyborg Manifesto," which is suspicious — to put it mildly — of the capacity of reason to steer, much less optimize, what it hath wrought.) (WOLFE, 2010, p. xiii)

Anu. Lit., Florianópolis, v. 19, n. 1, p. 10-29, 2014. ISSNe 2175-7917 
transformou-se a Inglaterra é desvelado: a monarquia caiu e o estado é governado por uma figura totalitária, o warden of England ${ }^{7}$, Xan Lypiatt, primo de Theo.

Neste mundo infértil, surge uma espécie de culto à juventude através dos benefícios dados ao grupo dos Omegas, jovens nascidos em 1995, último ano de fertilidade no planeta. Os Omegas marcam sua posição social, tida e vista como superior pelo resto da população, no corpo:

\begin{abstract}
As mulheres Omega possuem uma beleza diferente, remota, apática, sem animação ou energia. Elas têm um estilo distinto, o qual outras mulheres nunca copiam. Elas usam seu cabelo comprido e solto, suas testas delimitadas com uma trança ou fita, lisa ou estampada. É um estilo que só combina com rostos classicamente belos, com testa alta e larga, olhos bem espaçados. Como seus correspondentes masculinos, elas aparentam ser incapazes de compaixão humana. Homens e mulheres, os Omegas são uma raça a parte, favorecidos, propiciados, temidos, vistos com um espanto meio supersticioso. Em alguns países, nos dizem, eles são ritualmente sacrificados em ritos de fertilidade ressuscitados depois de séculos de civilização superficial. Eu às vezes me pergunto o que nós, Europeus, faríamos se tivéssemos notícia de que essas oferendas queimadas tiverem sido aceitas pelos deuses antigos e uma criança viva nascer. ${ }^{8}$ (JAMES, 1992, p. 10-11, tradução nossa)
\end{abstract}

É importante ver a contradição corporal ao redor dos Omegas. Eles são vistos como um grupo semiperfeito e, como tal, deveriam assumir o papel de últimos representantes da humanidade em todos os sentidos possíveis. No entanto, os Omegas abandonaram sua humanidade e tornaram-se corpos vazios, incapazes de manter qualquer tipo de sentido de comunidade (e, consequentemente, de humanidade) com outras pessoas que não sejam Omegas. O corpo Omega é fisicamente, psicologicamente e socialmente estéril.

Ironicamente, em um mundo onde não há nascimentos por mais de vinte e cinco anos, o governo encoraja os idosos a cometerem suicídio assistido em cerimônias rituais chamadas Quietus. Tais cerimônias, das quais Theo lembra "uma imagem .... Idosos vestidos de branco sendo empurrados em cadeiras de roda ou ajudados a entrar na barcaça, as vozes cantantes agudas e débeis, o barco navegando lentamente no crepúsculo, uma cena sedutora e

\footnotetext{
${ }^{7} \mathrm{O}$ termo warden pode referir-se a um administrador mas, na grande maioria das vezes, seu uso refere-se a um guarda ou, mais comumente, a um carcereiro, o que torna ainda mais evidente a ideia da distopia como uma prisão.

${ }^{8}$ The female Omegas have a different beauty, remote, listless, without animation or energy. They have their distinctive style which other women never copy. They wear their hair long and loose, their foreheads bound with braid or ribbon, plain or plaited. It is a style which suits only the classically beautiful face, with its high forehead and large, widely spaced eyes. Like their male counterparts, they seem incapable of human sympathy. Men and women, the Omegas are a race apart, indulged, propitiated, feared, regarded with a half-superstitious awe. In some countries, so we are told, they are ritually sacrificed in fertility rites resurrected after centuries of superficial civilization. I occasionally wonder what we in Europe will do if news reaches us that these burnt offerings have been accepted by the ancient gods and a live child has been born. (JAMES, 1992, pp. 10-11)
} 
pacífica, habilmente fotografada e iluminada"9 (JAMES, 1992, p. 47, tradução nossa), indicam outra ironia paradoxal desta distopia: os corpos envelhecidos precisam ser eliminados não para darem lugar a corpos jovens mas, simplesmente, porque a distopia não tolera corpos inaptos. O culto aos corpos jovens mas socialmente inaptos dos Omegas faz a intolerância à velhice ainda mais irônica: ela refere-se à necessidade de criar um novo sentido para a história e para o materialismo histórico que seja separado do continuum que está morrendo com a perda da fertilidade. Os corpos originalmente estéreis ainda são mais centrais para a manutenção de uma ilusão de relações sociais na Inglaterra distópica do romance do que aqueles que tornaram-se estéreis por conta da idade (e das circunstâncias nunca esclarecidas no texto).

No entanto, a trama principal está na relação entre Theo e um grupo de contrarrevolucionários autodenominados The Five Fishes. A principal intenção do grupo é derrubar o governo autoritário de Lypiatt e o grupo aproxima-se de Theo devido a sua relação com o "carcereiro". O historiador concorda ajudá-los apenas para poder aproximar-se de Julian, uma integrante dos Five Fishes. Julian, no entanto, tem motivos para preocupar-se com a política socio-corporal imposta pelo regime distópico. Theo a descreve como segue:

Seu cabelo, escuro e voluptuoso, um castanho intense com luzes douradas, estava penteado para trás e disciplinado em um trançado curto e grosso. Uma franja pendia sobre sua testa alta, sardenta. Sua pele era muito clara para alguém com um cabelo tão escuro, uma mulher cor de mel, de pescoço longo e bochechas erguidas, olhos grandes cuja cor [Theo] não conseguia determinar sob sobrancelhas fortes e retas, um nariz fino e alongado, levemente arqueado, e uma boca larga, lindamente formatada. Era um rosto pré-Rafaelita. Rossetti teria adorado pintá-la.... Ela estava sem luvas e ele pôde ver que sua mão esquerda era deformada. Os dedos do meio e o indicador eram fundidos em um cotoco sem unha e a parte de cima de sua mão estava grosseiramente inchada. Ela a segurava com a mão direita como se a estivesse protegendo ou confortando. Não havia qualquer esforço em escondê-la. Ela podia inclusive estar clamando sua deformidade para um mundo que se tornara intolerante a defeitos físicos. Mas ao menos, ele pensou, ela tinha uma compensação. Ninguém que fosse deformado fisicamente ou mental ou fisicamente doente estava na lista de mulheres através de quem a nova raça nasceria se um homem fértil fosse descoberto. Ela estava, ao menos, salva dos exames semestrais, longos e humilhantes aos quais todas as mulheres saudáveis abaixo dos 45 anos de idade eram submetidas. ${ }^{10}$ (JAMES, 1992, p. 39, tradução nossa)

\footnotetext{
9 "one picture . . . : White-clad elderly being wheeled or helped on to the low barge-like ship, the high, reedy singing voices, the boat slowly pulling away into the twilight, a seductively peaceful scene, cunningly shot and lit". (JAMES, 1992, p. 47)

${ }^{10}$ Her hair, dark and luscious, a rich brown with flecks of gold, was brushed back and disciplined into a short, thick pleat. A fringe fell over a high, freckled forehead. She was light-skinned for someone so dark-haired, a honey-coloured woman, long-necked with high cheekbones, wide-set eyes whose colour [Theo] couldn't determine under strong straight brows, a long narrow nose, slightly humped, and a wide, beautifully shaped mouth. It was a pre-Raphaelite face. Rossetti would have liked to paint her... She was gloveless and he could see that her left hand was deformed. The middle and forefinger were fused into a nail-less stump and the back of her hand was grossly swollen. She held it cradled in her right as if comforting or supporting it. There was no effort to
} 
O corpo deformado de Julian só tem a sua existência permitida na sociedade por conta de sua suposta esterilidade. Humanidade, na distopia de James, é relacionada não somente à esperança da reprodução mas, também, a uma existência corporal tida como apta. Somente os humanos vistos como perfeitos são submetidos a testes periódicos de fertilidade e como Julian não preenche o requisito da perfeição física, ela é dispensada de tais exames.

No entanto, a tensão cresce quando Julian, a mulher tida como fisicamente imperfeita e, logo, incapaz de geral a vida que poderia salvar a humanidade depois de anos de infertilidade, engravida. A gravidez é vista com extrema cautela pelo grupo pois eles temem que o filho de Julian seja retirado da mãe ao nascer (uma vez que ela é fisicamente deformada e, portanto, é tida como subumana em um mundo pós-humano) e usado para fins políticos pelo sistema autoritário inglês. No entanto, tal fato remete às distopias modernas da primeira metade do século XX pois a gravidez de Julian também é um exemplo de "indivíduo versus o sistema" onde os limites e imperfeições corporais são fatores complicadores para o elemento desafiador (os mais clássicos exemplos de tal imagem são, talvez, a úlcera varicosa de Winston Smith em 1984 e a mãe desdentada e decadente de John o Selvagem em Admirável Mundo Novo) mas que acabam tendo impacto no sistema.

Se em The Children of Men, o impacto do transhumanismo é observado pelo seu oposto - ou seja, pelo foco nos corpos inaptos — na distopia de Kazuo Ishiguro, Não Me Abandone Jamais (2005), também situada na Inglaterra, o impacto é na criação de elementos infra-humanos para a manutenção do ideário transhumanista. No entanto, ao contrário das distopias clássicas, que situam-se no futuro, Ishiguro transgride o princípio da eucronia situando sua narrativa nas décadas de 1980 e 1990. Nesse universo, os humanos desenvolveram a técnica da clonagem após o fim da II Guerra Mundial e os clones são enviados para colégios internos por todo o país, onde permanecem até completarem o ciclo básico de ensino, por volta dos 18 anos (e, por esse motivo, durante todo o romance, eles são tratados por "alunos"). Depois dessa idade, eles são expostos ao mundo e seu propósito central, ao atingirem a maturidade física, é o de servirem de doadores de órgãos para cidadãos não-clonados (ou sujeitos plenos dentro de tal visão de sociedade). Outra possibilidade de

hide it. She might even have been proclaiming her deformity to a world which had become increasingly intolerant of physical defects. But at least, he thought, she had one compensation. No one who was in any way physically deformed, or mentally or physically unhealthy, was on the list of women from whom the new race would be bred if ever a fertile male was discovered. She was, at least, saved from the six-monthly, timeconsuming, humiliating re-examinations to which all healthy females under forty-five were subjected. (JAMES, 1992, p. 39) 
existência para os clones, ainda que transitória, é como cuidadores dos doadores após o início do processo de doações (os órgãos são coletados conforme a necessidade dos receptores).

O romance é narrado por uma dessas clones, Kathy H. (a eles, é atribuído um nome próprio mas somente uma inicial de sobrenome, aparentemente aleatória, o que marca, desde o início de sua existência, o papel social que lhes é imposto), que reconta suas experiências em Hailsham, uma das escolas para os clones, os quais recebem uma educação forte nas humanidades e nas artes. O que segue é um Bildungsroman de uma personagem cuja humanidade é questionável. A tensão do romance gira justamente ao redor de tal questionamento: Kathy H. apaixona-se por Tommy D. e ambos saem em busca das antigas diretoras de Hailsham no sentido de comprovarem a veracidade de seus sentimentos através da arte por eles produzida, a partir de um rumor que, no evento de um amor verdadeiro entre os clones, poder-se-ia adiar o início dos processos de doação por dois anos. A busca por Madame, a figura misteriosa que coletava os trabalhos de arte dos alunos de Hailsham, poderia confirmar tais rumores. $\mathrm{O}$ encontro com Madame, no entanto, trouxe a confirmação de um dilema ético a que os clones foram poupados durante seus anos de formação:

“...Mas você fez suas perguntas, meu caro rapaz. Vamos responder à mais simples, e talvez essa responda a todas as outras. Por que nós levávamos os trabalhos artísticos de vocês embora? Por que fazíamos isso? Você falou uma coisa bem interessante agora há pouco, Tommy. Quando estava conversando com a Marie-Claude. Você disse que era porque a arte revelaria como vocês eram. Como vocês eram por dentro. Foi isso que você disse, não foi? Bem, pois saiba que não está muito distante da verdade. Nós levávamos seus trabalhos porque achávamos que eles revelariam a alma de vocês. $\mathrm{Ou}$, para esclarecer melhor a questão, fazíamos isso para provar que vocês tinham uma alma.... Quando a Marie-Claude [a diretora de Hailsham] e eu começamos, não havia estabelecimentos como Hailsham. Nós fomos um dos primeiros, junto com Glenmorgan House. Depois de alguns anos surgiu a Fundação Saunders. Juntos, nos tornamos um movimento pequeno mas com voz ativa, que se opôs ao programa de doações na forma como estava sendo gerido. Mais importante ainda, demonstramos para o mundo que, quando criados num ambiente humano e culto, os alunos podiam se tornar tão sensíveis e inteligentes quanto qualquer ser humano normal. Antes disso, todos os clones - ou alunos, como nós preferíamos chama-los - existiam apenas para abastecer a ciência médica. Nos primeiros tempos, logo depois da guerra, isso era tudo o que vocês representavam para a grande maioria. Objetos obscuros em tubos de ensaio.... Para responder à sua pergunta, Tommy. Era por esse motive que colecionávamos a arte que faziam. Nós selecionávamos o que havia de melhor e organizávamos mostras especiais. No final dos anos 70, no auge de nossa influência, montávamos eventos enormes por todo o país. Compareciam ministros, bispos, tudo quanto é tipo de gente famosa aparecia para nos prestigiar. Faziam discursos, concediam verbas. 'Olhem, aqui está!', nós podíamos dizer. 'Olhem só toda esta arte! Como é que vocês ousam dizer que essas crianças não são inteiramente humanas?' . ..” (ISHIGURO, 2005, p. 311-313)

A resposta de Madame questiona, justamente, a centralidade ética dos corpos transumanos clonados: a partir do momento em que eles são seres produzidos através de procedimentos tecnológicos com o único intuito de servirem como mercadoria, teriam os 
clones um status de seres humanos plenos dentro daquela sociedade? A arte produzida pelos clones durante seus anos de formação serviria, então, para convencer os humanos "plenos" de que os clones também poderiam ser vistos como tal. No entanto, a atribuição de cidadania (ou humanidade) plena a eles seria contraproducente e paradoxal pois implicaria em abandonar a visão de que os clones são produtos criados unicamente para prolongar a existência dos seres humanos. Isso explica não só o fato de que os clones não têm sobrenome (e, logo, não pertencem a nenhum microgrupo de seres por afinidade consanguínea e/ou cultural) mas, principalmente, o da sua exclusão do convívio social durante os anos de formação. Como os clones não são sequer produtos plenos (uma vez que nem todos os órgãos são passíveis de doação), eles devem ficar afastados para que a sociedade não seja confrontada com os possíveis aspectos éticos envolvidos em sua criação.

Se em Não Me Abandone Jamais, o transumanismo é pretexto para a manutenção orgânica da vida humana, a distopia imaginada por Margaret Atwood na trilogia Maddaddam traz outras questões envolvidas diretamente com a construção tecnológica do transumanismo. Nos romances Oryx \& Crake (2004), The Year of the Flood (2010) e Maddaddam (2013) ${ }^{11}$, Atwood cria um universo distópico onde as grandes corporações multinacionais substituíram o estado em todas as suas atribuições - da educação à segurança pública - criando verdadeiros feudos chamados compounds (complexos), cercados por muros e protegidos das áreas chamadas pleeblands, as periferias pobres dos complexos ricos e avançados tecnologicamente.

No entanto, Oryx \& Crake inicia-se depois da destruição da civilização como era conhecida (causada pelo evento denominado "dilúvio seco" [waterless flood] por vários grupos religiosos). O narrador, Jimmy, acredita ser o único ser humano sobrevivente à pandemia causada por seu então amigo Glenn (que responde pelo apelido Crake), um cientista e engenheiro genético prodigioso que acreditava que o planeta só poderia ser salvo a partir da extinção dos seres humanos e do repovoamento por hominídeos criados geneticamente, chamados Crakers. O propósito de Crake, ao criar seus seres, era o de eliminar todos os traços culturais que, de certa forma, "desanimalizam" os humanos, começando com a eliminação de uma ideia de Deus. O teólogo Russel Blackford, em seu ensaio intitulado "The Great Transition: Ideas and Anxieties" (2013) problematiza o status atual do pensamento transumanista afirmando que:

\footnotetext{
${ }^{11}$ Os dois primeiros romances foram traduzidos e publicados no Brasil como Oryx e Crake e O Ano do Dilúvio.
} 
Uma das lições da história é para termos cuidado com sistemas de pensamento apocalípticos que dizem ter o apoio de Deus ou da História. Se Deus ou a História estão do seu lado, demandando mudanças cataclísmicas, seus fins podem sugerir meios terríveis. Ninguém foi preso, esterilizado, mantido sem comida ou queimado na fogueira em nome do transumanismo e, talvez, isso jamais acontecerá. Transumanistas não possuem Céu ou Inferno, nenhum outro mundo ou normas de conduta ou credo. Isso tudo é tranquilizador. O perigo, no entanto, está em a História tornar-se o seu Deus. ${ }^{12}$ (BLACKFORD, 2013, p. 428, tradução nossa)

Como já dito, Crake tem o intuito de eliminar o "ponto-G" ("G-spot”) no cérebro" (ATWOOD, 2004, p.157), sendo que o G em questão é God, Deus em inglês, elemento que simboliza toda a cultura humana e que, portanto, é a grande causa da decadência humana. Logo, os Crakers aproximam-se mais dos aspectos animais e biológicos do que humanos e culturais. Eles têm, por exemplo, períodos e rituais de acasalamento onde o ventre das fêmeas (ou mulheres, uma vez que eles têm base genética humana) torna-se azul:

[u]ma vez que é apenas o tecido azul e os feromônios por ele liberados que
estimulam os machos, não existe mais amor não correspondido hoje em dia, nada
mais de luxúria frustrada; nada mais de sombras entre o desejo e o ato. A corte
inicia-se à primeira cheirada, à primeira aparição tímida de azul, com os machos
presenteado as fêmeas com flores - da mesma maneira que os pinguins presenteiam
com pedras arredondadas. Ao mesmo tempo, eles se satisfazem com erupções
musicais, como aves canoras. Seus pênis ficam azul-claros para combinar com os
abdomens das fêmeas e eles fazem uma espécie de dança de pinto azul, membros
eretos balançando de um lado pra outro, em uníssono.... Dentre os tributos florais, a
fêmea escolhe quatro flores e o ardor sexual dos candidatos perdedores se dissipa
imediatamente, sem ressentimentos. Então, quando o azul de seu abdômen alcança
seu tom mais escuro, a fêmea e seu quarteto procuram um lugar afastado e fazem
tudo até que a mulher engravide e sua cor azul desapareça. E é isso.
Nada mais de Não quer dizer sim, de qualquer forma, pensa o Homem-das-Neves.
Nada mais de prostituição, de abuso sexual a crianças, de discussão sobre o preço,
de cafetões, de escravas sexuais. Nada mais de estupro. ${ }^{13}$ (ATWOOD, 2004, p. 165,
tradução nossa)

A tensão se estabelece no momento em que os Crakers têm contato com Jimmy e, a partir disso, surge uma necessidade natural, quase orgânica de um mito de origem que

12 One of history's lessons is to beware of apocalyptic thought systems that claim the endorsement of God or History. If God or History are on your side, demanding cataclysmic change, your ends can suggest terrible means. No one has been imprisoned, sterilized, starved, or burned at the stake in the name of transhumanism, and perhaps it will never happen. Transhumanists have no Heaven and Hell, no other world, or canons of conduct, or comprehensive creed. That is all reassuring. The danger, though, is if History becomes their God. (BLACKFORD, 2013, p. 428)

${ }^{13}$ [s]ince it's only the blue tissue and the pheromones released by it that stimulate the males, there's no more unrequited love these days, no more thwarted lust; no more shadow between the desire and the act. Courtship begins at the first whiff, the first faint blush of azure, with the males presenting flowers to the females - just as male penguins present round stones. At the same time, they indulge in musical outbursts, like songbirds. Their penises turn bright blue to match the blue abdomens of the females and they do a sort of blue-dick dance number, erect members waving to and fro in unison .... From amongst the floral tributes the female chooses four flowers, and the sexual ardour of the unsuccessful candidates dissipates immediately, with no hard feelings left. Then, when the blue of her abdomen has reached its deepest shade, the female and her quartet find a secluded spot and go at it until the woman becomes pregnant and her blue colouring fades. And that is that.

No more No means yes, anyway, thinks Snowman. No more prostitution, no sexual abuse of children, no haggling over the price, no pimps, no sex slaves. No more rape. (ATWOOD, 2004, p. 165)

Anu. Lit., Florianópolis, v. 19, n. 1, p. 10-29, 2014. ISSNe 2175-7917 
explicasse uma possível cosmogonia pós-humana; ou seja: os Crakers naturalmente buscaram aquilo que lhes foi negado por seu criador. Jimmy vê-se na obrigação moral de ser uma espécie de apóstolo, no sentido epistemológico do termo e, a partir da condição orgânica dos hominídeos (pacifistas, herbívoros), ele constrói uma narrativa que tenta dar sentido à existência de tudo e todos. Essa cosmogonia é baseada em Crake e em Oryx, uma mulher misteriosa cuja origem é desconhecida e que torna-se não só um dos vértices de um triângulo amoroso com os dois amigos mas, também, é quem dá as lições de sobrevivência aos primeiros hominídeos criados a partir do laboratório de Crake. Nessa narrativa, os hominídeos tornam-se os filhos de Crake e os outros animais, os filhos de Oryx:

Os filhos de Oryx, os filhos de Crake. Ele deveria pensar em algo. Ajeite sua
história, mantenha ela simples, não vacile: era esse o conselho profissional dado
pelos advogados aos criminosos no julgamento. Crake fez os ossos dos Filhos de
Crake de coral da praia, e então ele fez sua carne de uma manga. Mas os Filhos de
Oryx nasceram se um ovo, um ovo gigante posto pela própria Oryx. Na verdade, ela
pôs dois ovos: um cheio de animais e aves e peixes e outro, cheio de palavras. Mas
o ovo cheio de palavras chocou primeiro e os Filhos de Crake já haviam sido
criados, e eles comeram todas as palavras porque estavam famintos, e assim não
sobraram palavras quando o segundo ovo chocou. E é por isso que os animais não
podem falar. ${ }^{4}$ (ATWOOD, 2004 , p. 96 , tradução nossa)

A criação da cosmogonia dos Crakers por Jimmy passa, necessariamente, pela construção de uma teogonia em um mundo transumano que deveria ser naturalmente ateu e agnóstico. A sobrevivência de elementos religiosos em um mundo pós-apocalíptico e transumano é o foco do segundo romance da trilogia, The Year of the Flood, cuja narrativa é cronologicamente paralela à de Oryx \& Crake mas centrada em um grupo religioso chamado God's Gardeners, que mescla elementos cristãos com sustentabilidade natural e vegana em sua espera pelo "dilúvio seco". Os poucos membros do grupo que sobrevivem à epidemia unem-se a Jimmy e aos Crakers no terceiro romance, Maddaddam, e a trama passa a gorar em torno da manutenção da construção da cosmogonia transumana.

A ironia nos romances de Atwood está na construção de corpos transumanos que deveriam abandonar os elementos culturais (contrariando o princípio fundamental do transumanismo que é a entrega ao desejo de consumo tecnológico para fins de melhoria e prolongamento da vida) mas que, naturalmente—ainda que, talvez, por “contágio" em função

\footnotetext{
${ }^{14}$ The Children of Oryx, the Children of Crake. He'd had to think of something. Get your story straight, keep it simple, don't falter: this used to be the expert advice given by lawyers to criminals in the dock. Crake made the bones of the Children of Crake out of the coral on the beach, and then he made their flesh out of a mango. But the Children of Oryx hatched out of an egg, a giant egg laid by Oryx herself. Actually she laid two eggs: one full of animals and birds and fish, and the other one full of words. But the egg full of words hatched first, and the Children of Crake had already been created by then, and they'd eaten up all the words because they were hungry, and so there were no words left over when the second egg hatched out. And that is why the animals can't talk. (ATWOOD, 2004, p. 96)
}

Anu. Lit., Florianópolis, v. 19, n. 1, p. 10-29, 2014. ISSNe 2175-7917 
do contato com seres humanos — começam a desenvolvê-los, iniciando com o domínio das narrativas orais e escritas. Pode-se especular que, ao final do terceiro romance da trilogia, os Crakers e os humanos remanescentes tornar-se-ão uma única sociedade (inclusive geneticamente pois três mulheres humanas terminam a narrativa esperando filhos dos hominídeos) que pode ou não trilhar o mesmo desenvolvimento histórico, cultural e material que os humanos tiveram.

Uma tendência que deve ser citada aqui é o grande número de romances distópicosmuitos dos quais formam trilogias ou tetralogias-publicados para um público-leitor adolescente. ${ }^{15}$ Mesmo neles, a centralidade do corpo transumano faz-se presente. Exemplos de tal tendência são a trilogia formada por The Hunger Games (2008), Catching Fire (2009) e Mockingjay (2010), de Suzanne Collins ${ }^{16}$, onde adolescentes são convocados a travarem uma batalha mortal em uma arena para deleite dos espectadores e têm seus corpos reconstruídos sempre que necessário para garantir a continuidade do espetáculo; a tetralogia Uglies (2005), Pretties (2005), Specials (2006) e Extras (2007), de Scott Westerfield ${ }^{17}$, onde adolescentes são forçados a passar por cirurgias corretivas visando a correção de tudo o que pode ser visto como imperfeição estética (como acne) ou funcional (altura, por exemplo); e a trilogia formada por Divergent (2011), Insurgent (2012) e Allegiant (2013), de Veronica Roth ${ }^{18}$, onde adolescentes são forçados a passar por rituais de iniciação que definirão a que grupo eles pertencerão para o resto de suas existências.

Para concluir, as distopias literárias mantêm o espírito utópico vivo, ainda que em sua modalidade transgressora, como definiu Mohr. Pelo menos nos exemplos de língua inglesa discutidos aqui, pode-se afirmar, também, que o gênero distópico talvez seja aquele mais sensível às mudanças culturais causadas pela crescente dependência física e cultural aos elementos tecnológicos criados pelo capitalismo tardio, os quais impactam direta e profundamente na essência do que entendemos por humano e humanismo. Mesmo em suas vertentes mais fantasiosas e especulativas, tais narrativas merecem profunda análise pois, tal como suas versões da primeira metade do século XX, elas também podem antecipar tendências futuras. $\mathrm{O}$ assustador aqui é que, uma vez que o centro nervoso das distopias contemporâneas está no corpo — ou seja, na esfera do indivíduo sócio-político — a responsabilidade pelas possíveis previsões trazidas pela literatura é, também, individual antes de ser coletiva.

\footnotetext{
${ }^{15}$ Para um estudo mais profundo sobre o assunto, ver HINTZ E OSTRY (2003) e BASU et al. (2013).

${ }^{16}$ Traduzidos e publicados no Brasil como Jogos Vorazes, Em Chamas e A Esperança, respectivamente.

${ }^{17}$ Traduzidos e publicados no Brasil como Feios, Perfeitos, Especiais e Extras, respectivamente.

${ }^{18}$ Traduzidos e publicados no Brasil como Divergente, Insurgente e Convergente, respectivamente.
} 


\section{Referências}

ATWOOD, Margaret. Oryx and Crake. New York: Anchor Books, 2004. In Other Worlds: SF and the Human Imagination. London: Virago Press, 2011.

BACCOLINI, Raffaella, MOYLAN, Tom. Introduction: Dystopia and Histories. In: Baccolini, Raffaella; Moylan, Tom. (Eds). Dark Horizons: Science Fiction and the Dystopian Imagination. New York: Routledge, 2003. 1-12.

BASU, Balaka et al. Contemporary Dystopian Fiction for Young Adults: Brave new teenagers. New York: Routledge, 2013.

BLACKFORD, Russell. The Great Transition: Ideas and Anxieties. In: MORE, Max.; VITAMORE, Natasha (Eds.). The Transhumanist Reader: Classical and Contemporary Essays on the Science, Technology, and Philosophy of the Human Future. Chichester: Wiley-Blackwell, 2013. p. 421-429.

CLAEYS, Gregory. The origins of dystopia: Wells, Huxley and Orwell. In: CLAEYS, Gregory (Ed.). The Cambridge Companion to Utopian Literature. Cambridge: Cambridge University Press, 2010. p. 107-131.

FUKUYAMA, Francis. The End of History and the Last Man. New York: Free Press, 1992.

HILÁRIO, Leomir Cardoso. Teoria Crítica e Literatura: a distopia como ferramenta de análise radical da modernidade. Anuário de Literatura, Florianópolis, v.18, n.2, p. 201-215, 2013.

HINTZ, Carrie; OSTRY, Elaine. (Eds.). Utopian and Dystopian Writing for Children and Young Adults. New York: Routledge, 2003.

ISHIGURO, Kazuo. Não Me Abandone Jamais. São Paulo: Companhia das Letras, 2005.

JAMES, P.D. The Children of Men. New York: Vintage Books, 1992.

JAMESON, Fredric. Archaeologies of the Future: The Desire Called Utopia and Other Science Fictions. London: Verso, 2005.

MARKS DE MARQUES, Eduardo. Dystopian Britain: Critical Utopia and the Politics of the Body in P.D. James's The Children of Men, Alfonso Cuarón's Film Adaptation, Children of Men, and Kazuo Ishiguro's Never Let Me Go. In: Anais do XIII Congresso Internacional da ABRALIC: Internacionalização do Regional. Campina Grande: ABRALIC. 2013a.

I Sing the Body Dystopic: Utopia and Posthuman Corporeality in P.D. James's The Children of Men. Ilha do Desterro, Florianópolis, n.65, p.29-48, jul/dez 2013b.

MOHR, Dunja M. Transgressive Utopian Dystopias: The Postmodern Reappearance of Utopia in the Disguise of Dystopia. Zeitschrift für Anglistik und Amerikanistik (ZAA), 55.1, p. 5-24, 2007.

SHELLEY, Mary. Frankenstein. London: Puffin Books, 2002.

TOWER SARGENT, Lyman. Utopianism - A very brief introduction. Oxford: Oxford UP, 2010. 
TURNER, Bryan. J. The Body and Society: Explorations in Social Theory. 3.ed. Los Angeles: Sage, 2008.

VIEIRA, Fatima. The Concept of Utopia. In: CLAEYS, Gregory (Ed.). The Cambridge Companion to Utopian Literature. Cambridge: U of Cambridge P, 2010. p. 3-27.

WOLFE, Cary. What is Posthumanism?. Minneapolis: University of Minnesota Press, 2010.

[Recebido em fevereiro de 2014 e aceito para publicação em abril de 2014]

From Political Centrality to the Centrality of the Transhuman Body: Movements of the third dystopian turn in literature

Abstract: Much has been discussed the political character of dystopian novels of the socalled second turn (from the end of the 19th century to the 1950s), which are seen especially as forms of strong critique to totalitarian political regimes. However, a new trend of dystopian novels, over the past 30 years, have discussed the impact of the desire created by late Capitalism over the transfiguration of the body, which has been central to the construction of post-human and transhuman ideas. This paper aims at discussing the changes found in dystopian literatures in English throughout the $20^{\text {th }}$ century in order to propose a third dystopian turn in literature, from the writings of Fredric Jameson about science fiction and utopia, in the last 30 years, centering on the multiple transfigurations of the body created from the imposition of desire by late Capitalism and its impact on the post-human and transhuman modes of thought. To do so, a number of examples from novels belonging to such a trend are briefly discussed in order to create a critical panorama to support the proposal.

Keywords: Dystopias. Post-humanism. Transhumanism. Utopia. Speculative fiction.

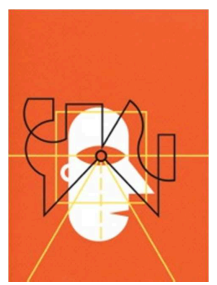

